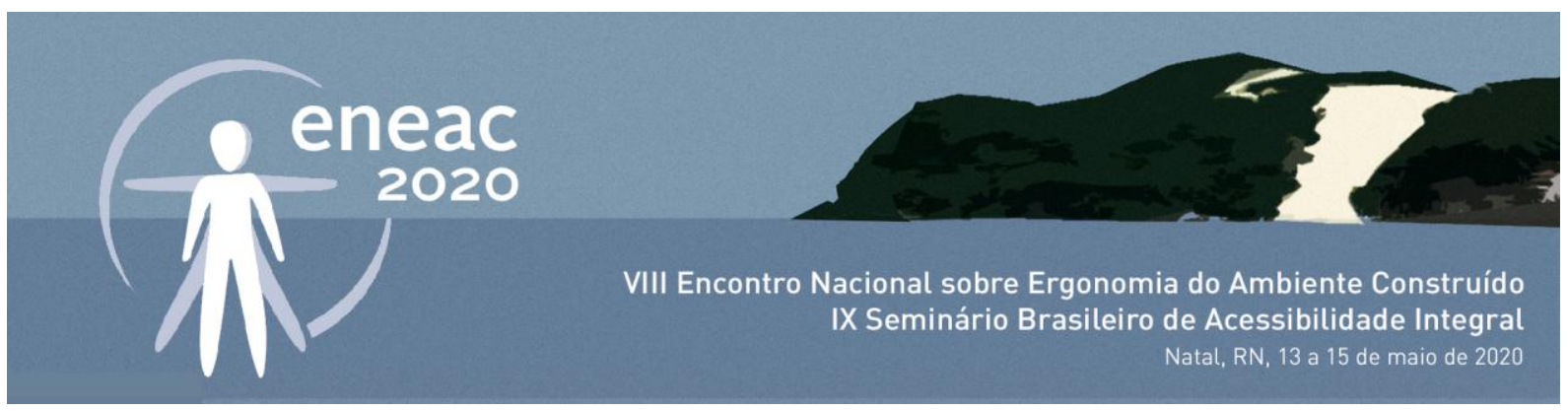

\title{
Avaliação da acessibilidade espacial: Um enfoque sobre o Centro de Educação da UFPB
}

\author{
Spatial accessibility assessment: a focus on the UFPB Education \\ Center
}

BRUNA RAMALHO SARMENTO

Doutora em Arquitetura e Urbanismo, UFPB, brunarsarmento@hotmail.com

CAROLINA DOS SANTOS PACHECO

Graduanda em Arquitetura e Urbanismo, UFPB, pachecocarol94@gmail.com

YASMIN SILVA DA NÓBREGA

Graduanda em Arquitetura e Urbanismo, UFPB, yasminnobrega@outlook.com

\section{RESUMO}

Este artigo apresenta o resultado da avaliação de acessibilidade espacial realizada no Centro de Educação (CE), localizado no campus I da UFPB. A análise teve início a partir de uma reunião com usuários do local, o que possibilitou um maior entendimento sobre as dificuldades espaciais enfrentadas. Em paralelo foi realizada a avaliação técnica com levantamento arquitetônico das edificações e aplicação de planilhas (Dischinger, Bins Ely e Piardi, 2012) a partir da realização de visitas técnicas. Posteriormente, foi realizada a sistematização dos dados, que foram compilados em tabelas ilustrativas e gráficos. Por fim, através de montagens visuais de mapas combinados com imagens do local, foram apresentadas propostas para alguns dos problemas encontrados, como a inserção de piso tátil nos passeios externos e internos, a colocação de placas indicativas em alto relevo e braile e a implantação de corrimão e/ou guarda-corpo em rampas e escadas. Com a análise, constatou-se que o CE apresenta aos seus usuários, além das dificuldades corriqueiras da vida universitária, uma complexidade para vivenciar o espaço de ensino, que continua a não contemplar os anseios dos usuários e as exigências vigentes na legislação.

PALAVRAS-CHAVE: acessibilidade, ambiente construído, instituições públicas de ensino superior.

\section{ABSTRACT}

This article presents the result of the spatial accessibility assessment carried out at the Education Center (CE), located on campus I of UFPB. An analysis started from a meeting with local users, or allowed a better understanding of the spatial difficulties faced. In parallel, a technical avaluation was carried out with the architectural survey of planners' editions and applications (Dischinger, Bins Ely and Piardi, 2012) based on technical visits. Subsequently, data were systematized, which were compiled into illustrative tables and graphs. Finally, through visual assemblies of maps combined with images of the place, applications were applied to some of the problems encountered, such as the 


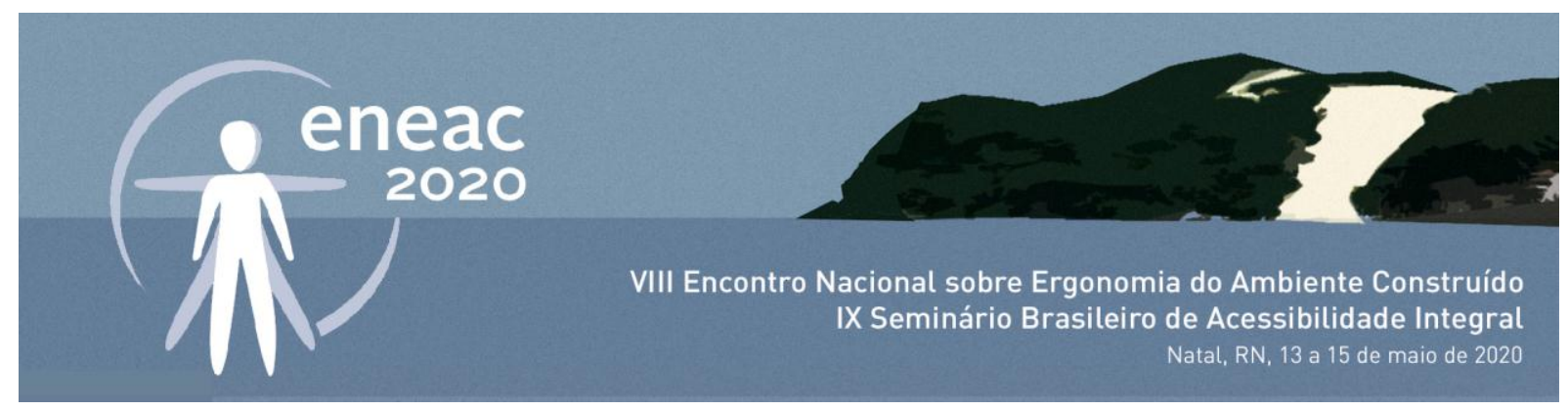

insertion of a tactile floor in the external and internal sidewalks, the placement of high relief and braille signs and the implementation of corrections and / or guardrails on ramps and stairs. With an analysis, see if the EC presents its users, in addition to the difficulties related to university life, a complexity to experience the teaching space, which continues not to contemplate the wishes of users and the requirements in force in the legislation.

KEYWORDS: accessibility, built environment, public institutions of higher education.

\section{INTRODUÇÃO}

Segundo a NBR 9.050 (ABNT, 2015), acessibilidade significa a possibilidade e condição de alcance, percepção e entendimento para utilização, com segurança e autonomia, de espaços, mobiliários, equipamentos urbanos, edificações, transportes, informação e comunicação, inclusive seus sistemas e tecnologias, bem como outros serviços e instalações abertos ao público, de uso público ou privado de uso coletivo, por pessoa com deficiência ou mobilidade reduzida.

O Decreto Federal n. 5.296 (BRASIL, 2004) estabelece normas gerais e critérios básicos para a promoção de acessibilidade e define pessoa com deficiência como aquela que possui limitação ou incapacidade para o desempenho de atividades, podendo ter deficiência física, auditiva, visual, mental e deficiência múltipla, enquanto que pessoas com mobilidade reduzida são aquelas que não se enquadrando no conceito de pessoa com deficiência, tenha dificuldade de movimentar-se, permanente ou temporariamente, gerando redução efetiva da mobilidade, flexibilidade, coordenação motora e percepção.

Baseando-se nessa descrição, Dischinger, Ely, Piardi (2012) classificam os componentes da acessibilidade espacial em quatro categorias: orientação espacial, comunicação, deslocamento e uso. A categoria de orientação espacial é determinada pelas características ambientais que possibilitam aos indivíduos "reconhecer a identidade e as funções dos espaços e definir estratégias para seu deslocamento e uso". O componente de comunicação diz respeito às possibilidades de troca de informações, garantindo o acesso, compreensão e participação dos usuários nas atividades existentes. Já as condições de deslocamento "referem-se à possibilidade de qualquer pessoa poder movimentar-se ao longo de percursos horizontais e verticais de forma independente, segura e confortável". O componente de uso se refere à possibilidade efetiva de uso dos espaços e dos equipamentos por todos os indivíduos.

No ambiente universitário o acesso à educação superior por pessoas com deficiência é garantido pela lei no 13.146, de 6 de julho de 2015 (BRASIL, 2015), que determina a igualdade de oportunidades e condições com as demais pessoas. Nesse sentido, os edifícios de uso coletivo são espaços responsáveis por receber pessoas das mais diversas características físicas e intelectuais (CAMBIAGHI, 2011).

Cada edifício público, de acordo com sua função, possui ambientes para a realização de atividades específicas a serem efetuadas por usuários com necessidades diversas. A relação de um espaço educacional e sua função é descrita por Duarte e Cohen (2004):

Pode-se considerar que, quando um único aluno for impedido de entrar numa biblioteca ou numa sala de aula pela simples existência de uma barreira física, a função educadora de uma 


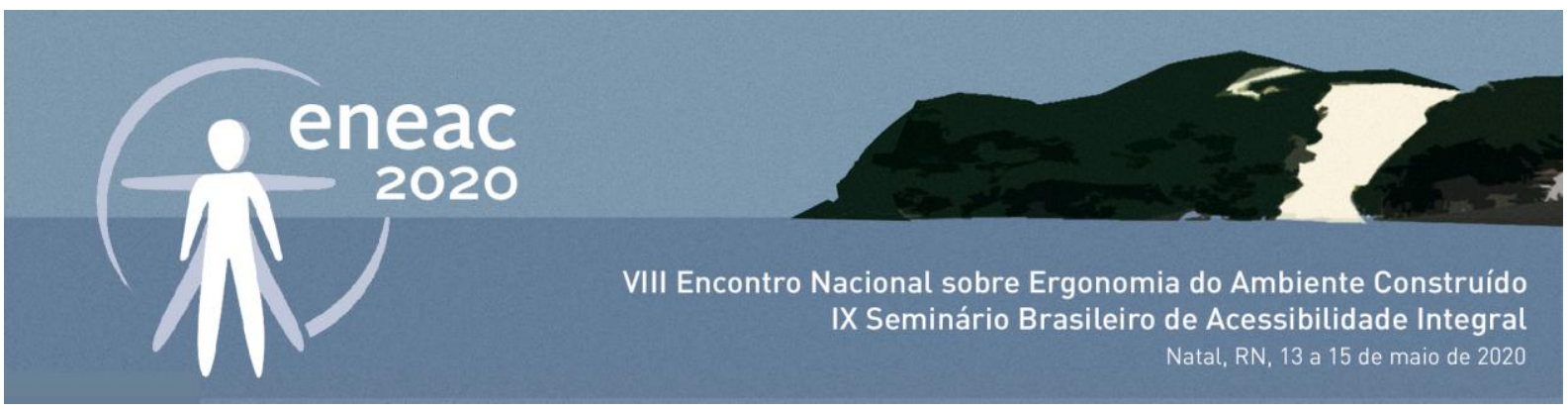

universidade estará sendo colocada imediatamente em xeque (DUARTE \& COHEN, 2004, p. 2).

Partido desse contexto, este artigo objeta analisar as edificações pertencentes ao Centro de Educação (CE), localizado no campus I da Universidade Federal da Paraíba (UFPB), em João Pessoa-PB (Figura 1). No CE são oferecidos os cursos de Psicopedagogia, Ciências das Religiões, Ciências Naturais, Pedagogia do Campo e Pedagogia Pronera, na modalidade presencial; e Pedagogia, nas modalidades presencial e virtual. O Centro ainda conta com os Núcleos de Educação Emocional - NEEMOC e Núcleo de Educação Especial - NEDESP.

Figura 1: Mapa da cidade de João Pessoa com destaque para o campus I da UFPB, e mapa do campus I da UFPB com destaque para o Centro de Educação.

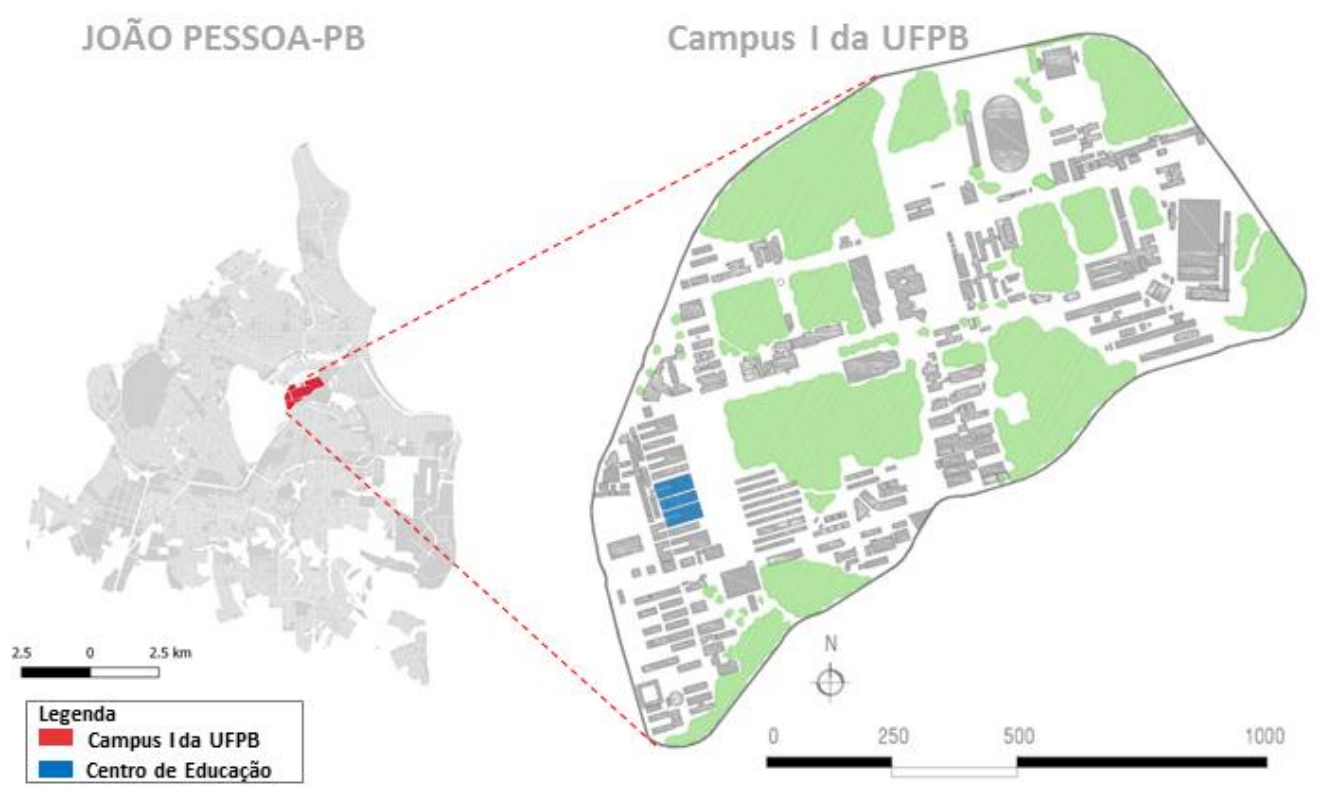

Fonte: Acervo pessoal, 2019.

Este trabalho é resultado de um serviço oferecido pelo Laboratório de Acessibilidade em parceria com o Grupo de Trabalho Acessibilidade Arquitetônica do Comitê de Inclusão e Acessibilidade da UFPB, que tem como objetivo prestar assistência técnica ao desenvolvimento de projetos arquitetônicos. O diagnóstico dos edifícios do CE foi solicitado pela coordenadora do NEDESP da UFPB, professora Isaura Maria, de forma a documentar as condições das instalações para intervenções futuras.

\section{METODOLOGIA}

O diagnóstico, realizado entre os meses de abril e maio de 2019, iniciou com uma reunião com alguns estudantes do $\mathrm{CE}$, que possuem deficiência visual, o que possibilitou um maior entendimento sobre as dificuldades espaciais enfrentadas diariamente por esses usuários, ampliando assim o campo de 


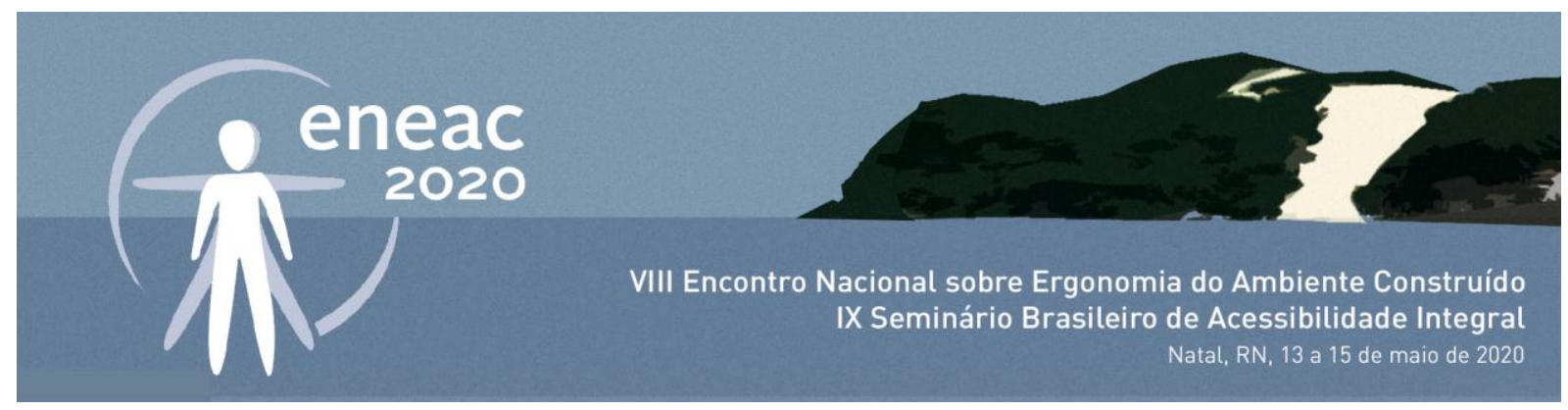

visão em relação à acessibilidade espacial dos edifícios em questão. Em paralelo, solicitou-se a Superintendência de Infraestrutura da UFPB os desenhos técnicos das edificações do Centro; sendo necessário, após a visita in loco, realizar atualização dos projetos disponibilizados, visto que estes não estavam de acordo com a situação encontrada. Para tanto, foi realizado um levantamento arquitetônico das edificações, com duração de três a quatro semanas, que possibilitou identificar que o CE possui um total de quatro edifícios, onde são desenvolvidas atividades de ensino, pesquisa, administrativas e similares.

A avaliação da acessibilidade espacial do local tomou por base a planilha proposta por Dischinger, Bins Ely e Piardi (2012) (Figura 2), que foi aplicada a partir da realização de visitas técnicas, que tiveram o auxílio de uma trena manual e uma trena eletrônica, além de registros fotográficos. Em relação às respostas das questões avaliadas, as positivas foram marcadas quando o elemento considerado possuía boa acessibilidade espacial, enquanto as respostas negativas indicam a presença de fatores que não estão de acordo com a norma. A opção "não se aplica/ inexistente" foi marcada nos casos em que o elemento avaliado não existe na edificação ou não se aplica ao objeto de estudo.

Figura 2: Ilustração da planilha aplicada.

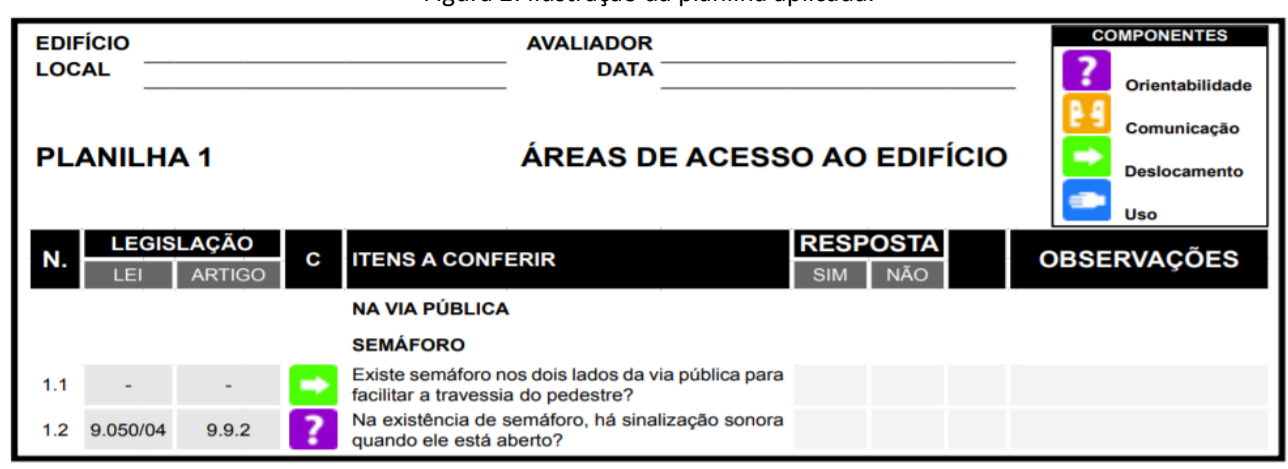

Fonte: Bins Ely e Piardi (2012).

Posteriormente, foi realizada a sistematização dos dados, demonstrados por tabelas ilustrativas (Figura 3), com colunas divididas em pontos positivos e negativos, baseado na NBR 9050 (ABNT, 2015). Fez-se uso de seis tabelas, as quais foram ordenadas seguindo o caminho de entrada do usuário nos edifícios desde sua chegada, a partir da via pública, até as atividades fins, e recebem as seguintes denominações: Áreas de acesso ao edifício (Tabela 1); Saguões, salas de recepção e espera (Tabela 2); Circulações horizontais (Tabela 3); Circulações Verticais (Tabela 4); Sanitários (Tabela 5); e Locais para Atividades Coletivas (Tabela 6). No caso presente, onde se trata de uma instituição de ensino, devido à multiplicidade de funções e a existência de edificações distintas, foi necessária a repetição do conjunto das tabelas para cada edifício.

A figura abaixo exemplifica como foi feito o diagnóstico de aproximadamente 25 elementos arquitetônicos e espaços analisados nos edifícios de acordo com a NBR 9050 (ABNT, 2015), caracterizando as situações encontradas nos edifícios do CE, sendo os pontos positivos os atribuídos correspondentes à norma, e os pontos negativos os aspectos em discordância. Dentre os elementos analisados, foram estudados: escadas, acessos, salas de aula, circulações horizontais e verticais, rampas, portas, sanitários e outros espaços ou elementos arquitetônicos. 


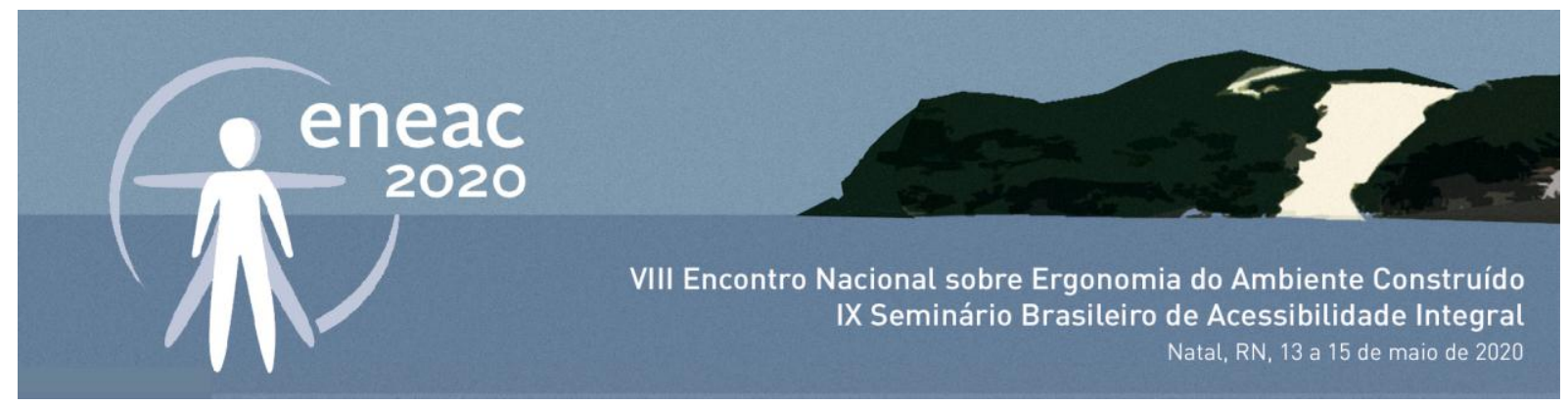

Figura 3: Exemplos das tabelas obtidas no diagnóstico realizado.

\begin{tabular}{l} 
CIRCULAÇÃO VERTICAL \\
\hline POSITIVO \\
\hline - A largura da escada, assim como a dos patamares é \\
de $1,30 \mathrm{~m}$ (A NBR 9050 exige no minimo de 1,20); \\
- A escada é feita em material antiderrapante e \\
incombustível; \\
- Existem patamares sempre que a escada vai mudar de \\
direção. \\
\hline \multicolumn{1}{c|}{ NEGATIVO } \\
- Os espelhos dos degraus são irregulares, chegando a \\
medir até 20cm (Segundo a NBR 9050, os espelhos devem ter \\
altura entre 16cm e 18cm); \\
- O corrimão está instalado em apenas um lado da \\
escada, estando a 96cm de altura em relação ao piso. \\
(Segundo a NBR 9050, os corrimãos devem ser instalados em \\
ambos os lados, a 0,92m e a 0,70m do piso, e suas extremidades \\
devem ter acabamento recurvado); \\
- Não possui guarda-corpo;
\end{tabular}

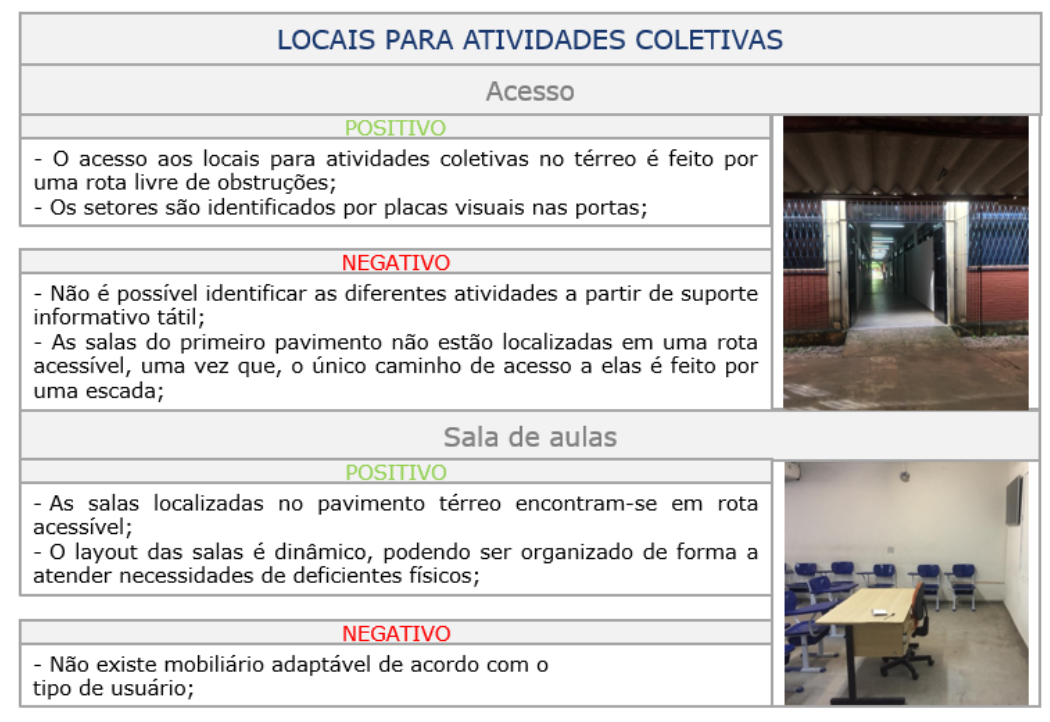

Fonte: Acervo Pessoal, 2019.

Também foi feita uma análise das informações, evidenciada em forma de gráficos e textos. Por fim, através de montagens visuais de mapas combinados com imagens do local foram apresentadas propostas de soluções para alguns dos problemas encontrados no CE.

\section{CENTRO DE EDUCAÇÃO DA UFPB}

O CE possui um total de quatro edifícios (Figura 4), com tipologia e morfologia semelhantes: os blocos A e $B$ possuem dois pavimentos (térreo e primeiro pavimento), o Bloco $C$ também apresenta dois pavimentos, mas o piso térreo conta com uma ampla área livre; e o Bloco Administrativo e de salas de aula possui apenas o pavimento térreo. 


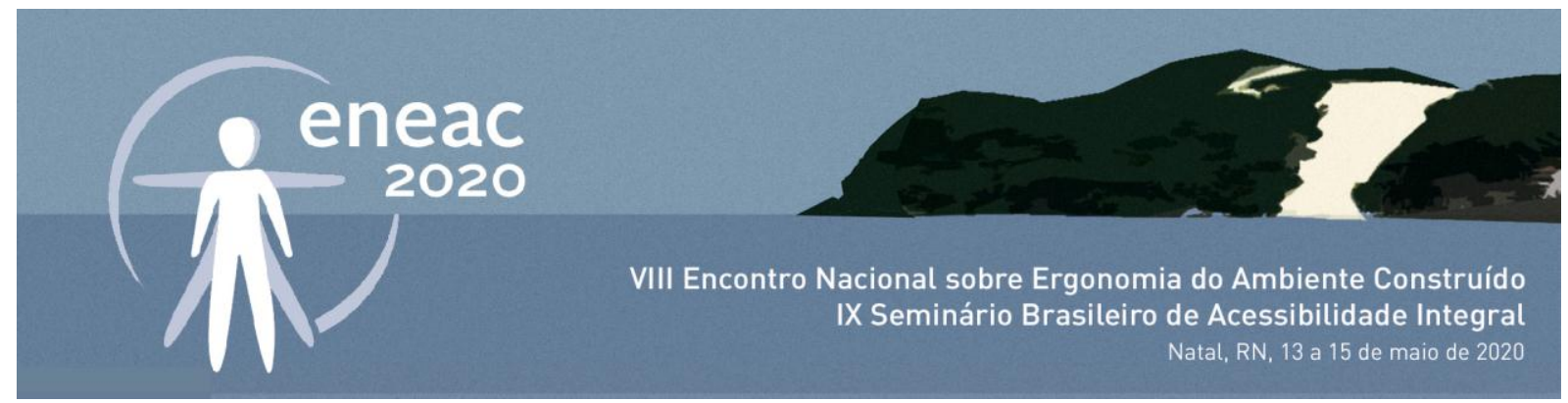

Figura 4: Planta baixa do térreo e fachada Leste das edificações analisadas, sendo elas respectivamente: blocos A e B (rosa); Bloco Administrativo de salas de aula (azul); e bloco C (amarelo).

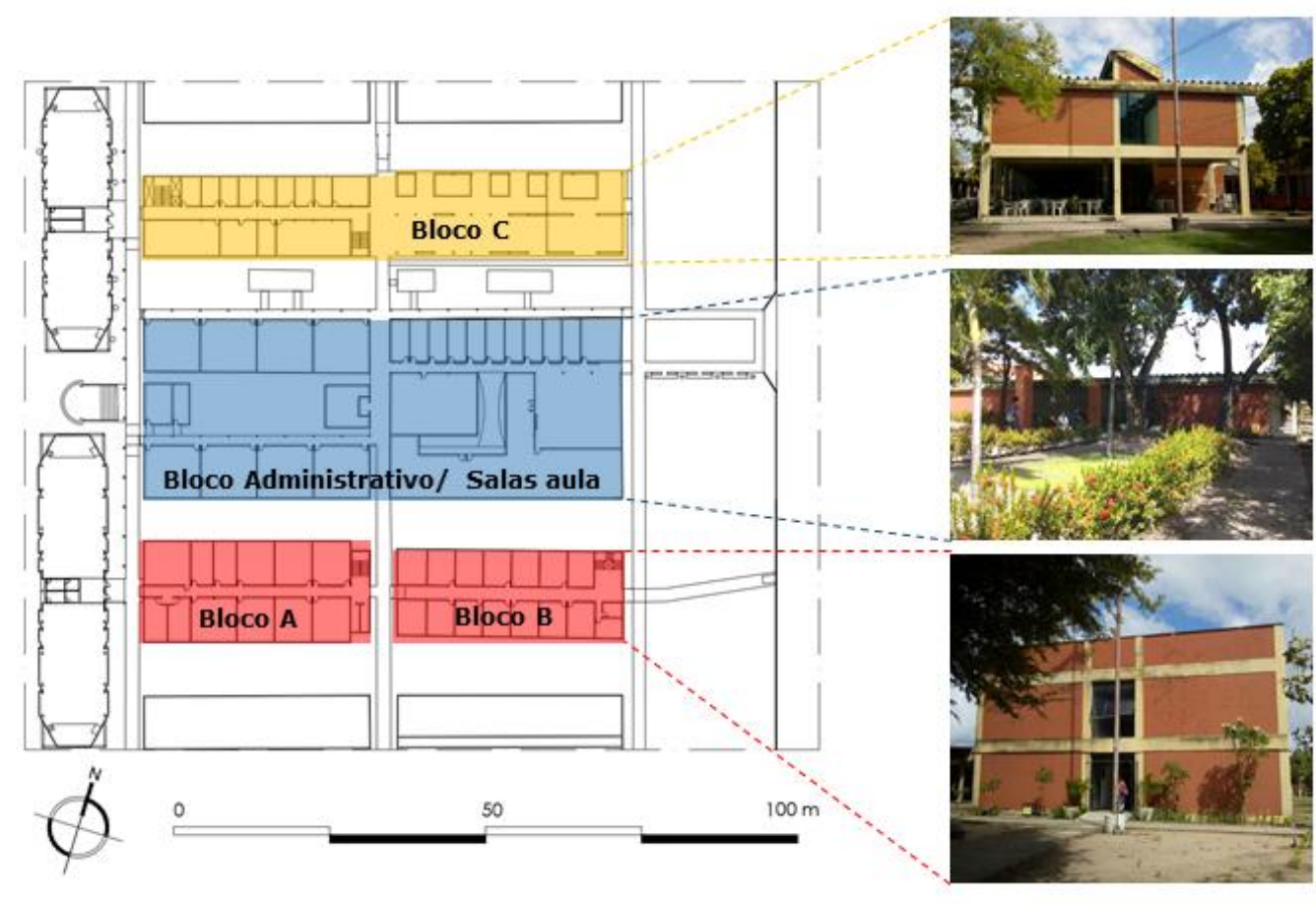

Fonte: Acervo pessoal, 2019.

Os blocos A e B são edificações de uso coletivo, tendo ambientes de sala de aula e laboratórios; secretarias, coordenações e departamentos dos cursos; e wc's. O pavimento superior dos blocos A e B não são acessíveis a todos os indivíduos, pois o acesso se dá por duas escadas, localizadas em uma das extremidades de ambos os edifícios.

No Bloco C têm-se dinâmicas distintas, enquanto o pavimento térreo é divido entre praça de alimentação, biblioteca setorial, sala de informática, sala de reuniões, e alguns ambientes de professores, o pavimento superior é composto em sua totalidade por salas direcionadas aos docentes. Assim como nos blocos A e B, o pavimento superior não é acessível a todos os indivíduos, pois o acesso ocorre por duas escadas localizadas em uma das extremidades e no centro da edificação.

O bloco administrativo concentra a maioria das coordenações dos cursos oferecidos no $\mathrm{CE}$, além da direção de Centro. Nos blocos de salas de aula, existem oito salas, com dimensões maiores que as dos blocos $A$ e $B$, podendo atender turmas com um número maior de alunos. Além de ter um bloco de banheiros no corredor principal, com wc's acessíveis. 


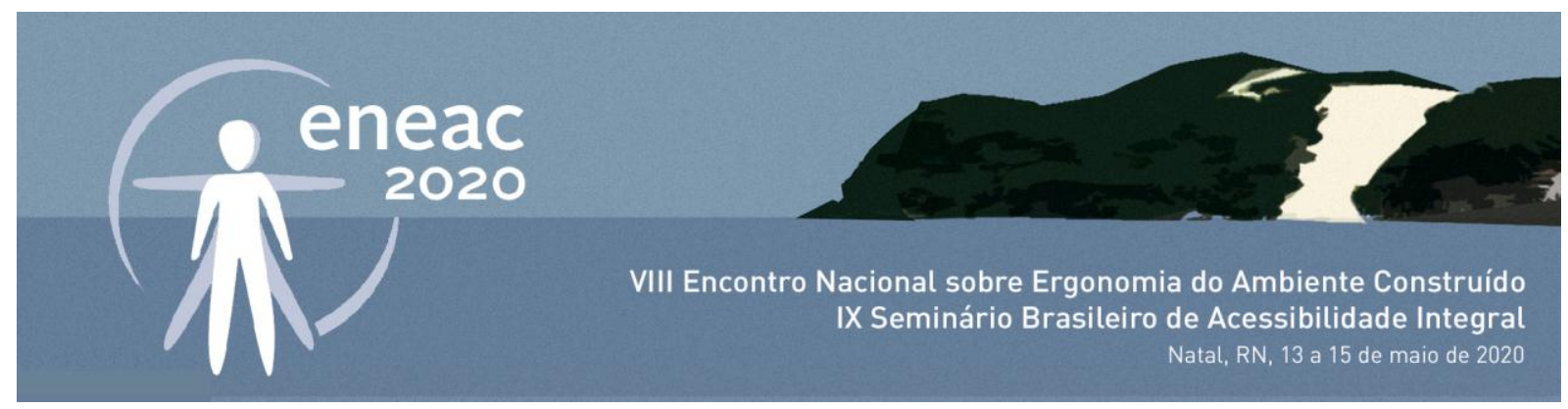

\section{DIAGNÓSTICO DE ACESSIBILIDADE}

Neste tópico serão apresentadas as etapas de análise: i) opinião dos usuários, obtida a partir de uma conversa com um grupo da comunidade universitária; ii) análise técnica, realizada com a aplicação da planilha de avaliação (Dischinger, Bins Ely e Piardi, 2012) e das tabelas ilustrativas, que foram aqui compiladas em tabelas quantitativas, com percentual de atendimento para cada componente de acessibilidade; iii) mapeamento da análise, onde os principais problemas identificados foram indicados nas plantas baixas dos edifícios avaliados; e iiii) ilustrações com propostas de melhorias para o espaço.

\section{Opinião de usuários}

No mês de abri de 2019 foi realizada uma conversa com a participação de 8 pessoas, dentre elas uma professora com mobilidade reduzida, 5 alunos com deficiência visual e 2 alunos apoiadores desses alunos deficientes. Na ocasião todos puderam expor suas experiências de locomoção dentro do Centro de ensino avaliado (Figura 5).

Figura 5: Tabela com apontamentos dos usuários sobre o CE.

\begin{tabular}{|c|c|}
\hline Pontos levantados & Relatos \\
\hline Estacionamento & $\begin{array}{l}\text { Foi declarada a necessidade de um estacionamento acessível mais próximo do bloco, tendo em vista que } \\
\text { seu o acesso as vagas existentes apresenta muitos desníveis. }\end{array}$ \\
\hline Auditório & Apresenta degraus altos. \\
\hline Escadas & $\begin{array}{l}\text { Sempre tentam evitar acesso por escadas, pois, assim como em todo o bloco, estas não apresentam } \\
\text { sinalização alguma. Os corrimãos estão frouxos, causando insegurança aos usuários. }\end{array}$ \\
\hline Corrimão & $\begin{array}{l}\text { A falta de corrimãos foi um dos pontos mais problemáticos, pois há muitos desníveis e rampas com } \\
\text { inclinação acima de } 8,33 \% \text {, e que são próximas a área com vegetação. }\end{array}$ \\
\hline Sinalização & $\begin{array}{c}\text { Biblioteca precisa ser mais bem sinalizada, os usuários se sentem excluídos, por ser um local de silêncio e } \\
\text { eles sentirem a necessidade de se comunicarem para poderem se locomover no ambiente; } \\
\text { O piso tátil é uma necessidade urgente segundo os voluntários. Um dos principais motivos é que a } \\
\text { NEDESP se localiza no bloco; } \\
\text { Foi dito que, por sempre existir pessoas que adquiriram recentemente a deficiência visual, seria } \\
\text { interessante a utilização de uma sinalização em braile combinada com letras em relevo; } \\
\text { Linhas antiderrapantes são essenciais, tendo em vista que quando o piso fica molhado a locomoção se } \\
\text { torna muito perigosa; } \\
\text { Foi proposta a instalação de "correntes guia" ao longo dos corredores, para que pessoas que adquiriram } \\
\text { recentemente a deficiência visual tivessem uma maneira mais pratica de se locomoverem; }\end{array}$ \\
\hline Banheiros & $\begin{array}{l}\text { Os banheiros apresentam uma pequena elevação nos seus acessos. Contudo, os alunos veem isto de } \\
\text { maneira positiva, pois é assim que eles identificavam a existência dos banheiros. }\end{array}$ \\
\hline Lanchonetes & $\begin{array}{l}\text { As mesas das lanchonetes são pequenas e baixas, fazendo com que um aluno cadeirante ou com nanismo } \\
\text { apresenta dificuldade na utilização, tendo em vista que o local é o ponto principal e mais prático para se } \\
\text { almoçar; Foi proposto também que houvesse uma preparação para as lanchonetes do bloco, pois muitas } \\
\text { vezes os alunos não têm condições de fazer o pedido e ficam se sentindo excluídos e impossibilitados de } \\
\text { serem atendidos. }\end{array}$ \\
\hline $\begin{array}{l}\text { Barreiras } \\
\text { atitudinais }\end{array}$ & $\begin{array}{l}\text { Apesar das várias críticas espaciais do bloco, as barreiras atitudinais foram consideradas as piores, a } \\
\text { exemplo de motos estacionadas em local irregular. }\end{array}$ \\
\hline Deslocamento & $\begin{array}{l}\text { As portas das salas de aula apresentam grades, que frequentemente ficam abertas no corredor, criando } \\
\text { barreiras; } \\
\text { No final do curso de pedagogia as salas de aula são menores, dificultando a locomoção. }\end{array}$ \\
\hline Manutenção & $\begin{array}{l}\text { O CE precisa de manutenção, como pisos novos que não causem o tropeço dos usuários e mobiliário } \\
\text { adequados, inclusive nas salas de aula. }\end{array}$ \\
\hline
\end{tabular}

Fonte: Acervo Pessoal, 2019. 


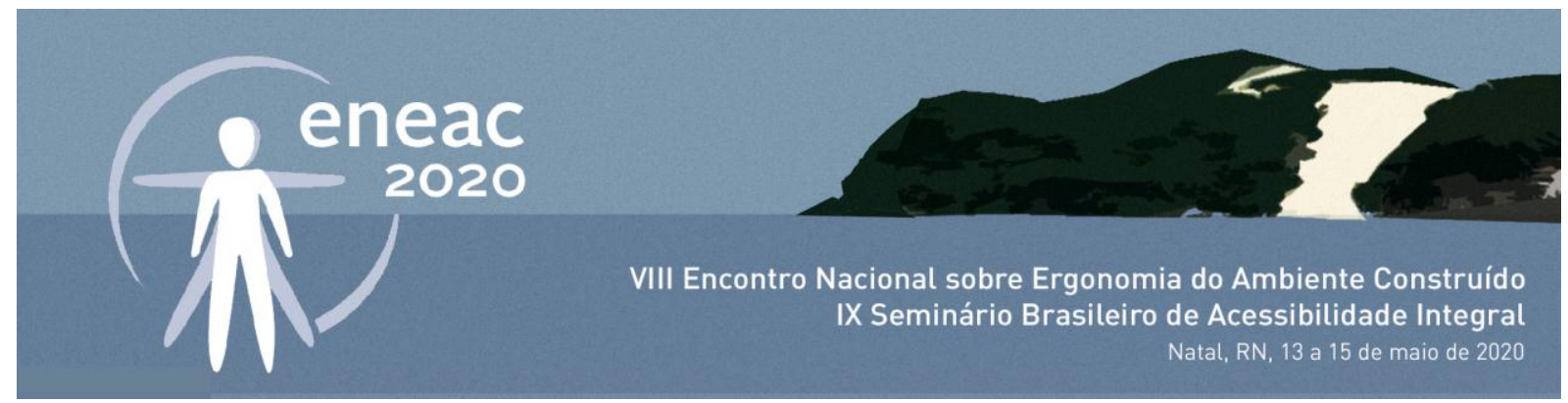

\section{Análise técnica}

A partir da aplicação das planilhas os dados levantados foram sistematizados e compilados em três conjuntos de blocos: Blocos A e B; Bloco C; e Bloco Administrativo e de salas de aula.

\section{-Blocos A e B}

Nos Blocos A e B do CE foi observado que apenas o componente de deslocamento teve porcentagem positiva. O componente de comunicação foi o que apresentou o pior resultado, seguido por orientabilidade e uso (Figura 6).

O resultado negativo do componente de comunicação indica que os blocos possuem baixo desempenho nas inter-relações entre usuários e edifício, visto que não oferecem nenhum terminal de tecnologia assistiva que auxilie o surdo e/ou mudo na comunicação com os funcionários. 0 sistema de alarme de incêndio sonoro ou luminoso também é inexistente em ambas as edificações.

Figura 6: Resultado final dos Blocos A e B computando o resultado de todas as categorias avaliadas.

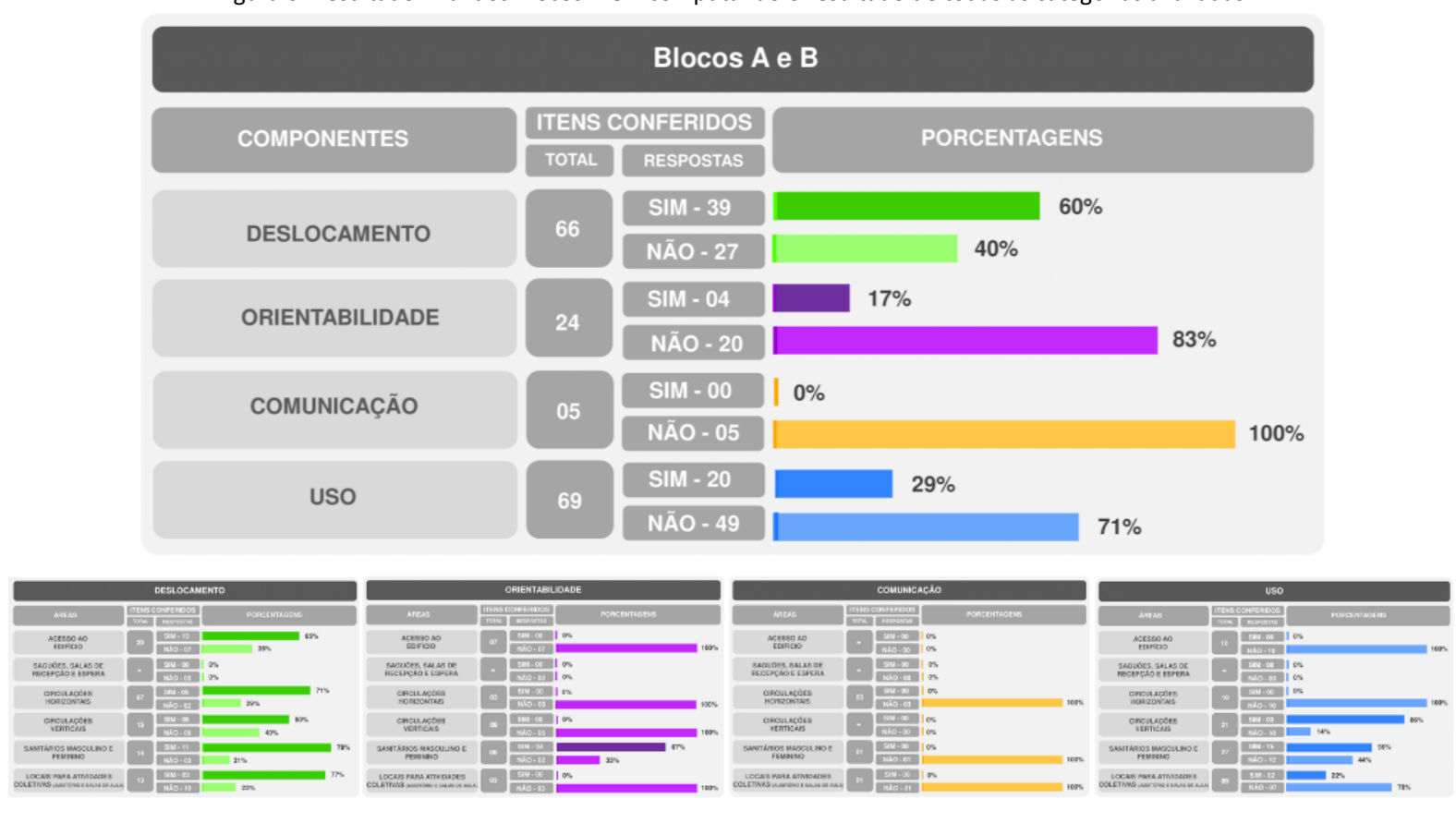

Fonte: Acervo Pessoal, 2019

\section{-Bloco C}

No Bloco $\mathrm{C}$ apenas o componente de deslocamento teve porcentagem de $61 \%$ positiva. Nesse caso, os componentes de orientabilidade e comunicação também foram os que obtiveram os piores resultados, tendo resposta negativa em todas as questões, seguida de quase $70 \%$ das respostas negativas nas questões de uso (Figura 7).

$\mathrm{O}$ quesito deslocamento no Bloco $\mathrm{C}$ teve três áreas com respostas positivas relevantes, sendo elas acesso ao edifício, circulações horizontais e circulações verticais. O único quesito que teve respostas negativas em sua totalidade foi o de locais para atividades coletivas. As questões positivas em sua 


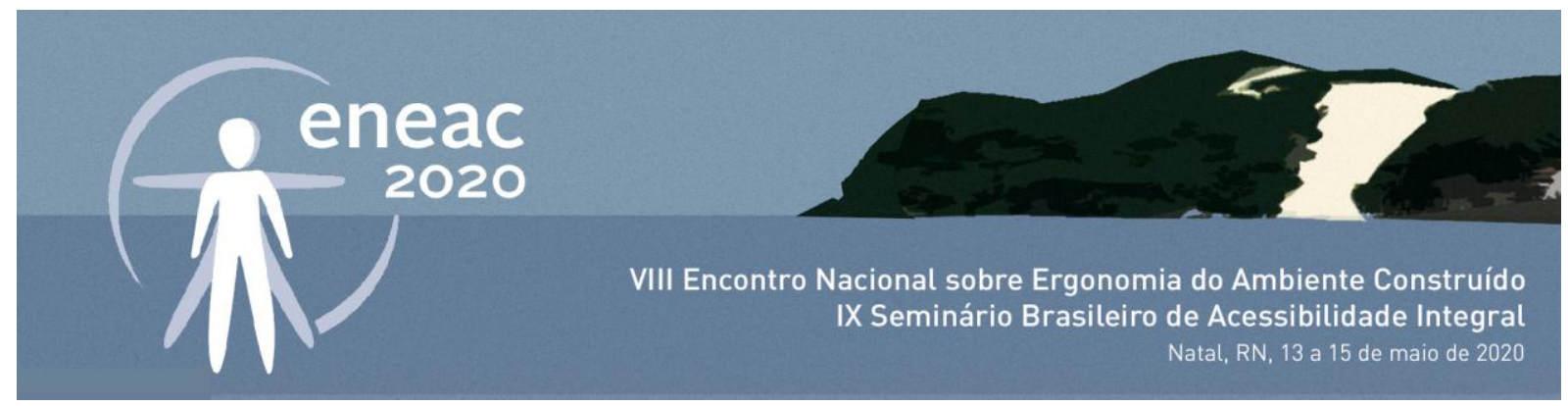

maioria se referem ao acesso efetuado por uma rota desobstruída, aos pisos antiderrapantes dos passeios, e ao cumprimento da norma em relação à largura de passeios, rampas e escadas. As respostas negativas advêm da inexistência de elevador, de inadequações das escadas e rampas, e do layout no espaço coletivo, no caso, na biblioteca.

Figura 7: Resultado final do Bloco C computando o resultado de todas as categorias avaliadas.
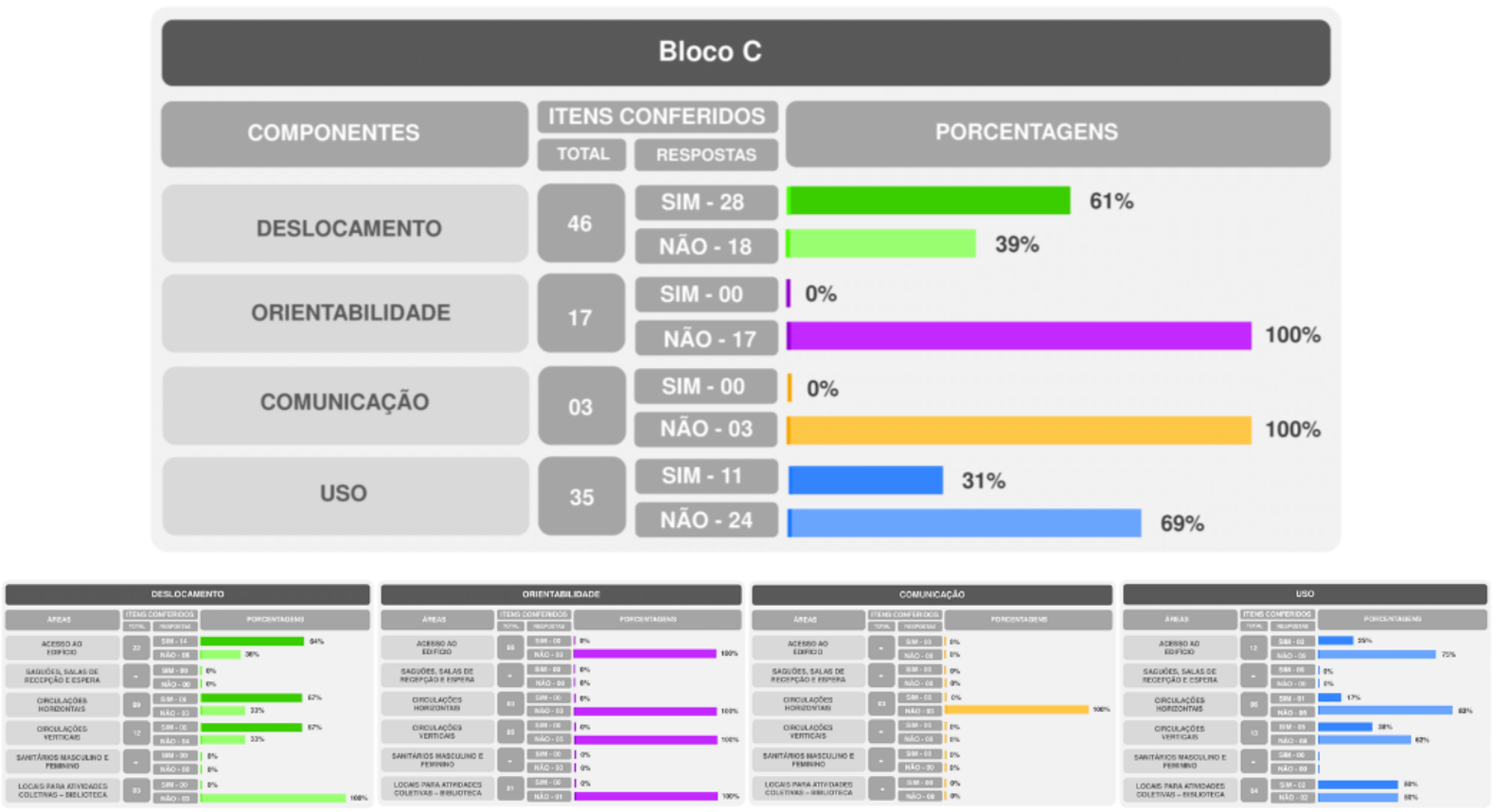

Fonte: Acervo Pessoal, 2019

\section{- Administrativo e de Salas de Aula}

No bloco administrativo e de sala de aula o resultado foi similar ao dos blocos $A$ e $B$, tendo o componente de comunicação como o mais prejudicado, visto que todas as suas respostas foram negativas, seguido por orientabilidade, com $80 \%$ de respostas negativas, e uso, com $63 \%$ de respostas marcadas "não". O único componente que obteve resultado positivo foi deslocamento (Figura 8).

O componente de orientabilidade apresenta todas as respostas negativas nos itens de 'saguões, salas de recepção e espera', 'circulações horizontais' e 'locais para atividades coletivas'. O item de 'acesso ao edifício' apresenta apenas uma questão positiva, sendo as demais todas negativas. Apenas no item de 'sanitários acessíveis' a orientabilidade teve resultado positivo. 


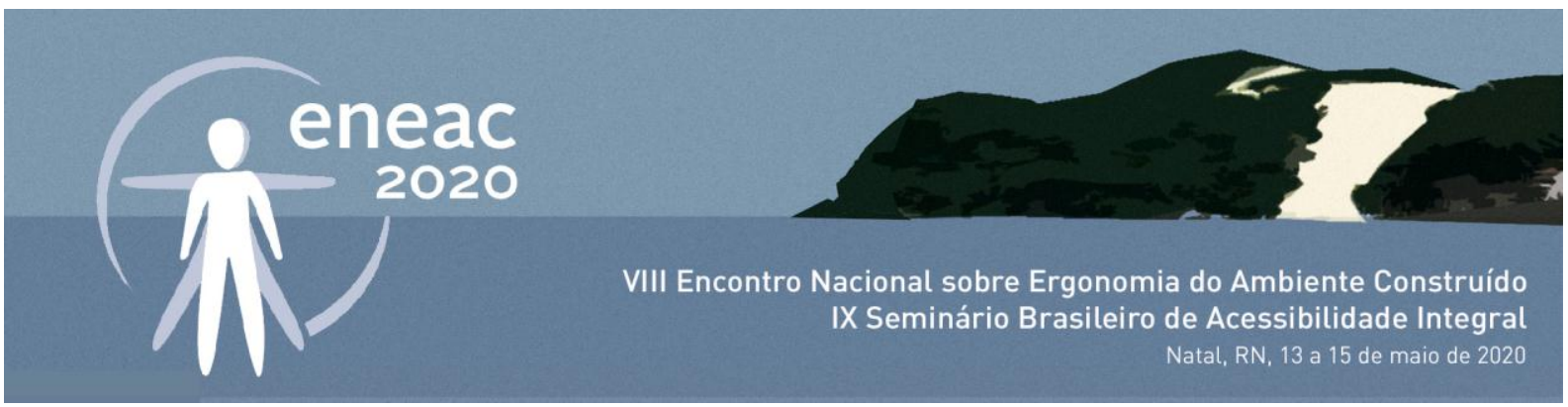

Figura 8: Resultado final do Bloco administrativo de salas de aula computando o resultado de todas as categorias avaliadas.

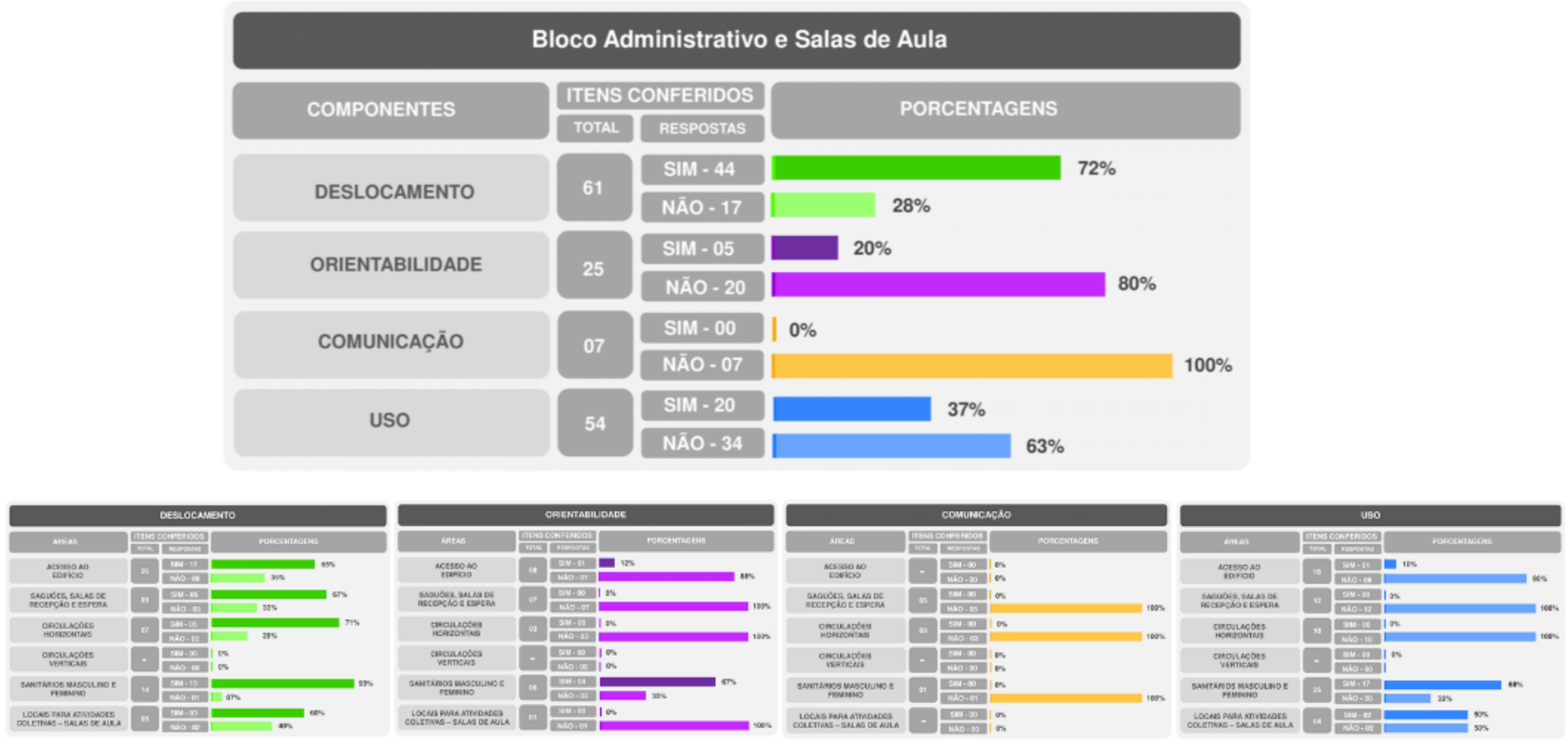

Fonte: Acervo Pessoal, 2019

\section{Mapeamento da análise}

A fim de facilitar a visualização do resultado final da análise, foi realizado um mapeamento demonstrando em planta baixa a localização dos principais problemas encontrados em cada um dos componentes de acessibilidade (Figuras 9, 10 e 11).

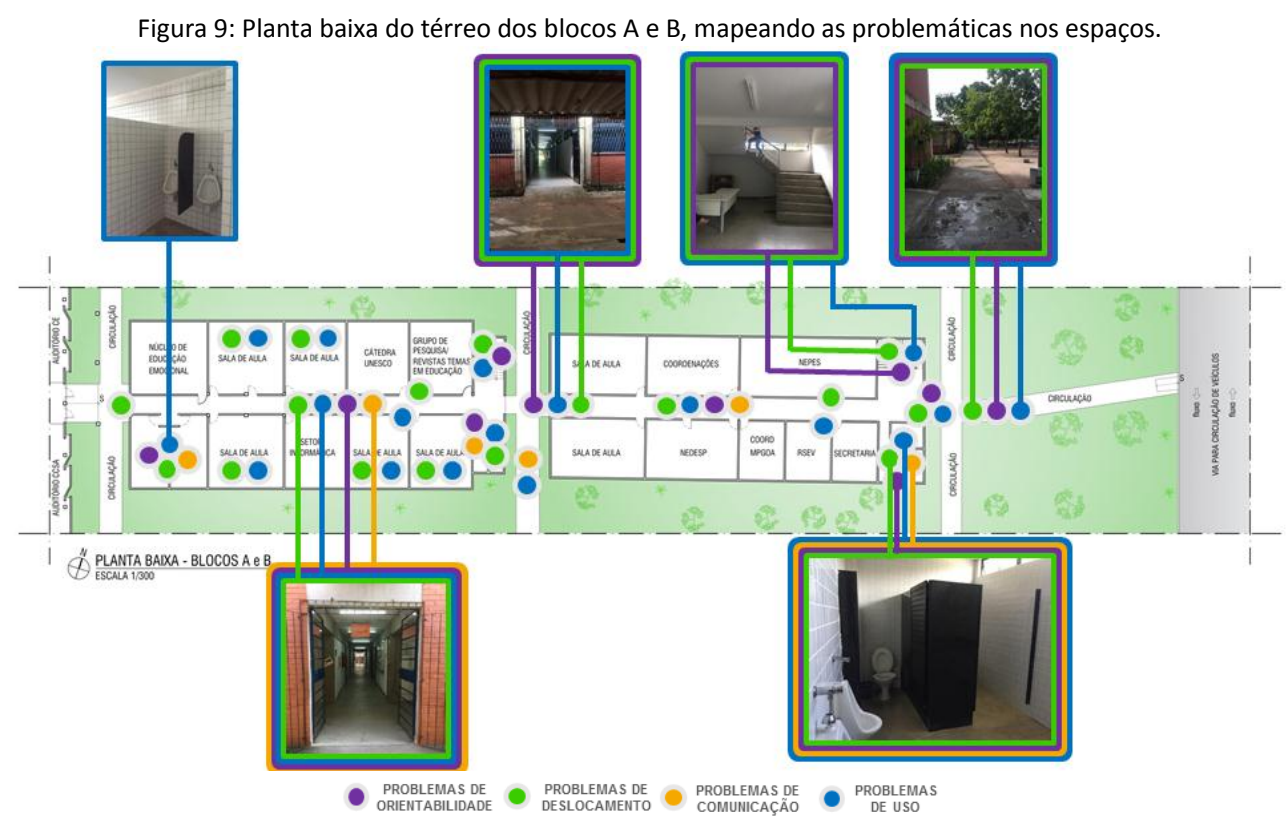

Fonte: Acervo Pessoal, 2019 

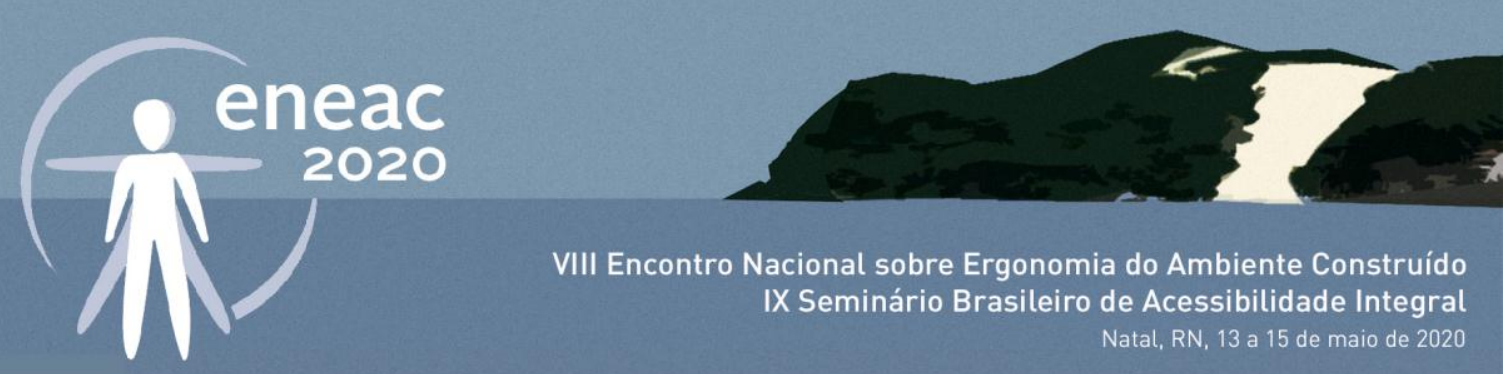

VIII Encontro Nacional sobre Ergonomia do Ambiente Construído IX Seminário Brasileiro de Acessibilidade Integral Natal, RN, 13 a 15 de maio de 2020

Figura 10 : Planta baixa do Bloco $\mathrm{C}$ mapeando as problemáticas nos espaços.

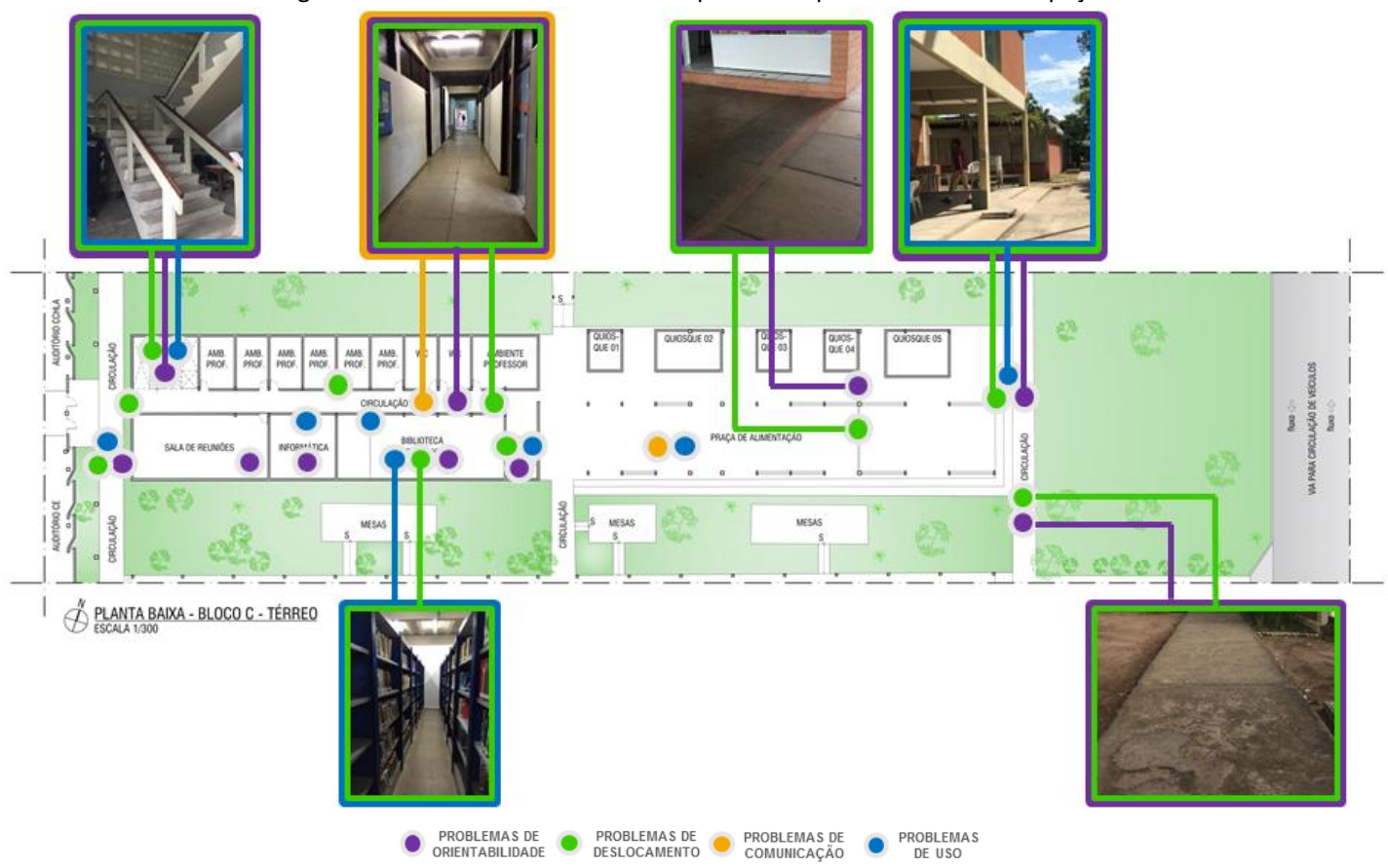

Fonte: Acervo Pessoal, 2019.

Figura 11: Planta baixa do Bloco Administrativo e Salas de Aula mapeando as problemáticas nos espaços.

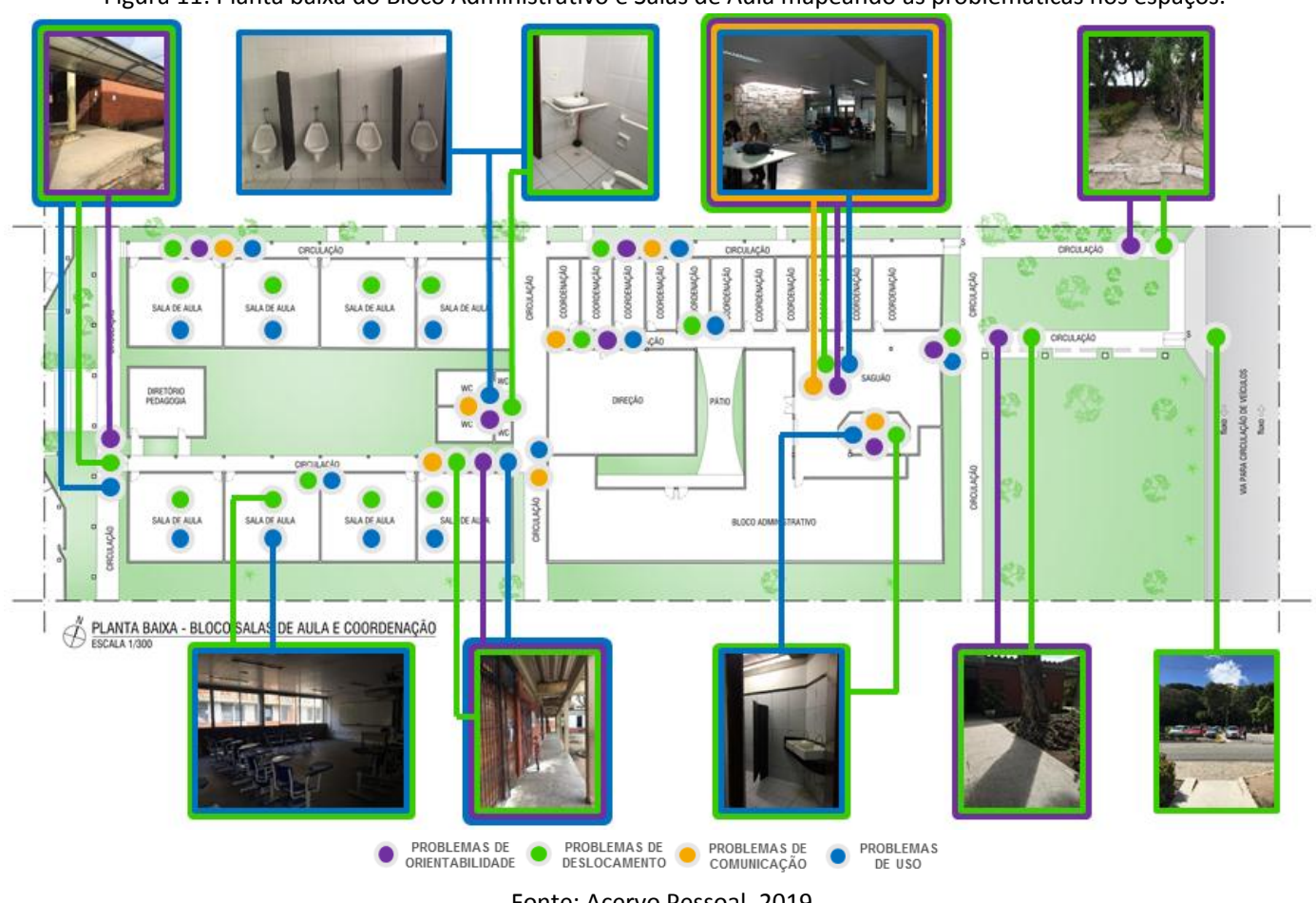

Fonte: Acervo Pessoal, 2019. 


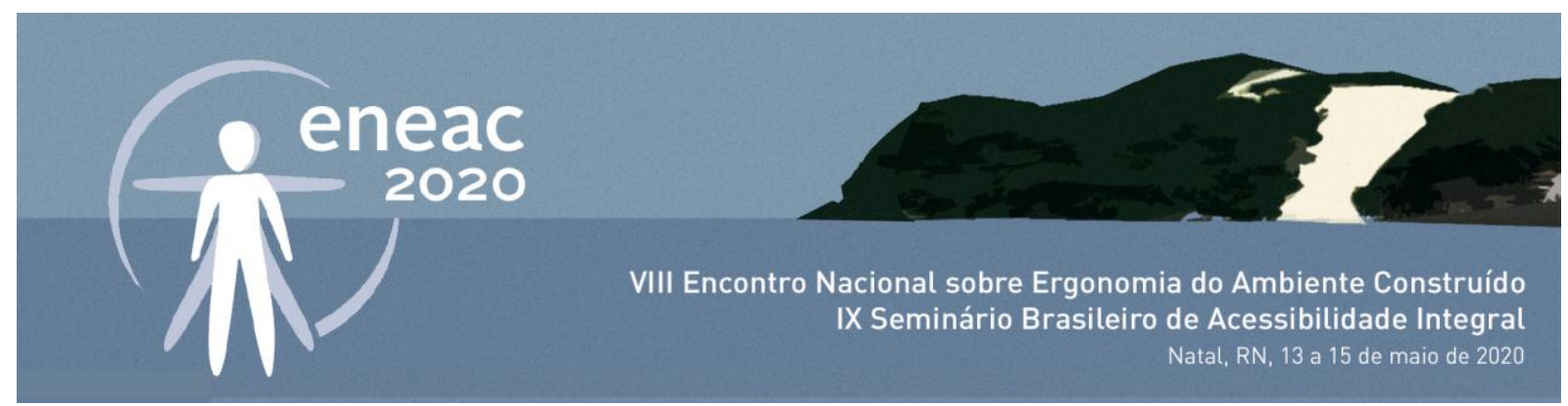

\section{Propostas de melhorias}

A seguir, são apresentadas simulações do que seriam soluções ideais referentes a cada um dos quatro componentes trabalhados nas planilhas e tabelas (Figura 12). Algumas dessas soluções seriam a inserção de piso tátil nas calçadas externas e internas, visando um melhor deslocamento, a colocação de placas em alto relevo e braile, para melhor orientabilidade e comunicação dos usuários, além da implementação de corrimãos em rampas e escadas.

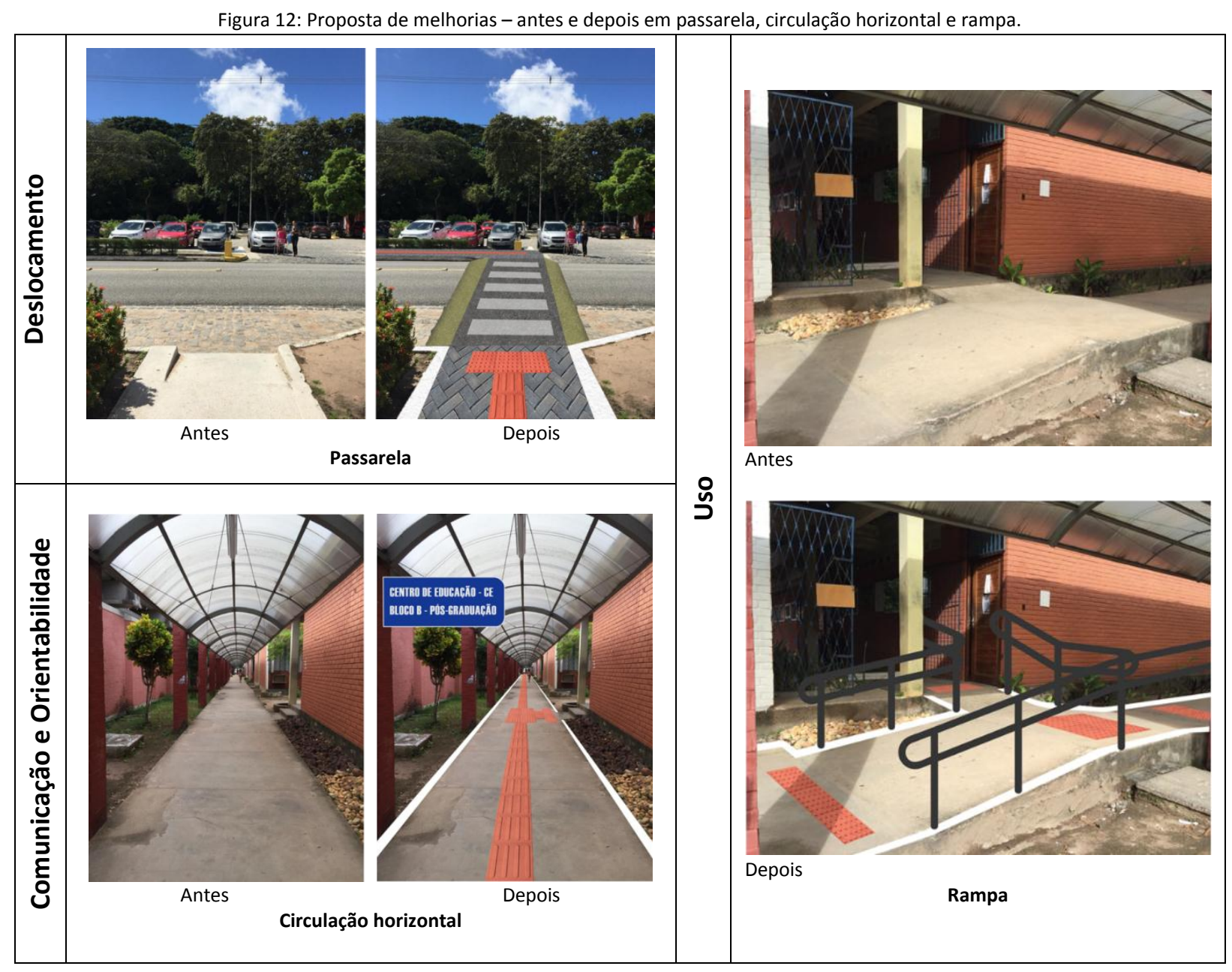

Fonte: Acervo Pessoal, 2019.

\section{CONSIDERAÇÕES FINAIS}

Com a análise do objeto de estudo a partir da opinião dos usuários e da avaliação técnica constatouse que os blocos A, B, C e Administrativo do Centro de Educação da UFPB, campus I, apresentam condições inadequadas de acessibilidade espacial, que dificultam o uso por parte de alunos, professores, servidores, e/ou visitantes com alguma deficiência e/ou com mobilidade reduzida. 


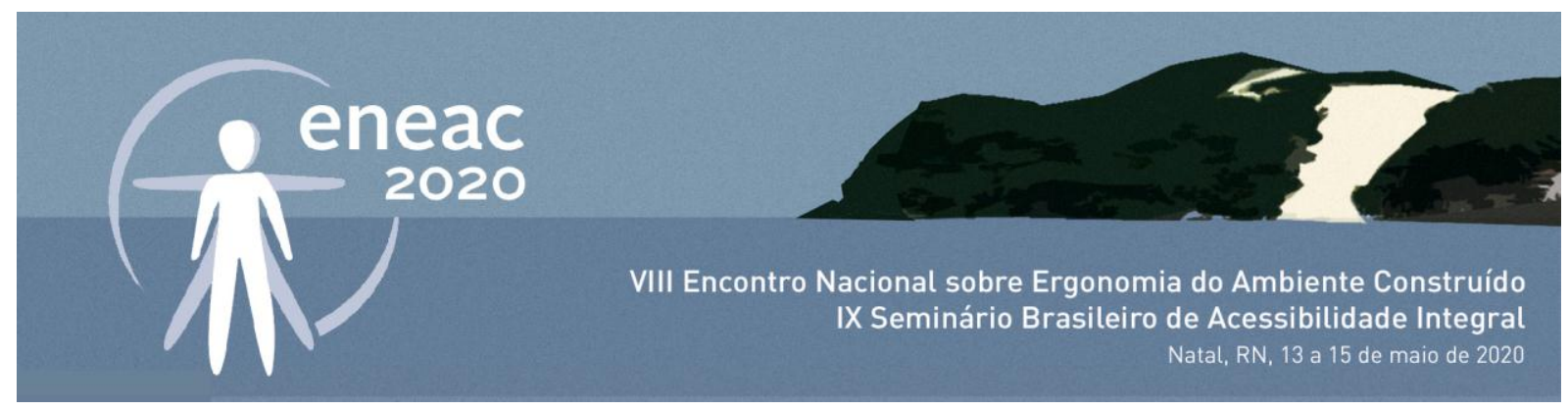

As edificações, tanto no exterior quanto internamente, necessitam de sinalização que indique ambientes, rotas, equipamentos e saídas de emergência. As informações existentes são demasiadamente insuficientes, não atendendo as recomendações legais, como o uso de recursos táteis (barras), visuais (placas) e sonoros (alarme) que possam dar suporte às diferentes atividades ali praticadas.

Os vãos de acesso não atendem a necessidade de uma pessoa com mobilidade reduzida, pois geralmente são feitas por rampas com inclinações acima do recomendado (8,33\%), sem corrimãos, balizas ou piso direcional. Além disso, para acesso aos ambientes internos, vários vãos possuem larguras inferiores a $80 \mathrm{~cm}$ (largura mínima para cadeirantes), as portas apresentam maçanetas em diferentes alturas (acima de 1,10m, que é o máximo permitido pela norma) e nem todas sendo do tipo alavanca.

Na circulação vertical foi observado que não há uma rota acessível, problema que poderia ser solucionado com a inserção de uma plataforma. Inclusive, os blocos B e C apresentam espaço para o mesmo. Além disso, as escadas são irregulares, com corrimãos, patamares, larguras e espelhos em divergência com a norma.

Os banheiros acessíveis localizam-se apenas no bloco administrativo, anterior as salas de aula, sendo seu principal problema o reduzido espaço para manobra frente a pia e a falta de alarme de emergência próximo à bacia. Os laboratórios, auditórios, bibliotecas e salas de aula voltadas para atividades coletivas não dispõem de rota acessível, sendo vários localizados no primeiro pavimento. Além disso, apresentam layout (disponibilização do mobiliário) inadequado e medidas para passagem insuficientes.

Diante das questões levantadas nesta avaliação é possível entender que, apesar da crescente preocupação com o desenho universal, os espaços analisados continuam a não contemplar os anseios dos usuários e exigências vigentes na legislação. Com isso, vários alunos encontram, além das dificuldades corriqueiras da vida universitária, complexidade para vivenciar no próprio espaço de ensino.

\section{REFERÊNCIAS}

ABNT - ASSOCIAÇÃO BRASILEIRA DE NORMAS TÉCNICAS. NBR 9050: Acessibilidade a edificações, mobiliário, espaços e equipamentos urbanos. Rio de Janeiro: ABNT, 2015. Disponível em:

<http://media.wix.com/ugd/50625b_186d3111107f4d33969d7e33afcac32d.pdf.> Acessado em 03 de agosto de 2019.

BRASIL. LEI NNo 13.146, DE 6 DE JULHO DE 2015. Institui a Lei Brasileira de Inclusão da Pessoa com Deficiência (Estatuto da Pessoa com Deficiência). Brasília: 2015. Disponível em: < http://www.planalto.gov.br/ccivil_03/_ato20152018/2015/lei/l13146.htm>. Acesso em: 27 mai.2019.

CAMBIAGHI, Silvana. Desenho Universal: Métodos e técnicas para arquitetos e urbanistas. Editora Senac São Paulo, São Paulo, 2007.

DISCHINGER, Marta; ELY, Vera Helena Moro Bins; PIARDI, Sonia Maria Demeda Groisman. Promovendo acessibilidade espacial nos edifícios públicos. Programa de Acessibilidade às Pessoas com Deficiência ou Mobilidade Reduzida nas Edificações de Uso Público. Ministério Público do Estado de Santa Catarina, Florianópolis, 2012. 